This item was submitted to Loughborough's Research Repository by the author.

Items in Figshare are protected by copyright, with all rights reserved, unless otherwise indicated.

\title{
Partnerships for improving water utility management in Africa
}

PLEASE CITE THE PUBLISHED VERSION

http://dx.doi.org/10.1680/muen.2007.160.1.1

PUBLISHER

(C) ICE Publishing Ltd.

VERSION

VoR (Version of Record)

LICENCE

CC BY-NC-ND 4.0

REPOSITORY RECORD

Mugabi, Josses, Sam Kayaga, and Cyrus Njiru. 2019. "Partnerships for Improving Water Utility Management in Africa". figshare. https://hdl.handle.net/2134/10030. 
This item was submitted to Loughborough's Institutional Repository (https://dspace.lboro.ac.uk/) by the author and is made available under the following Creative Commons Licence conditions.

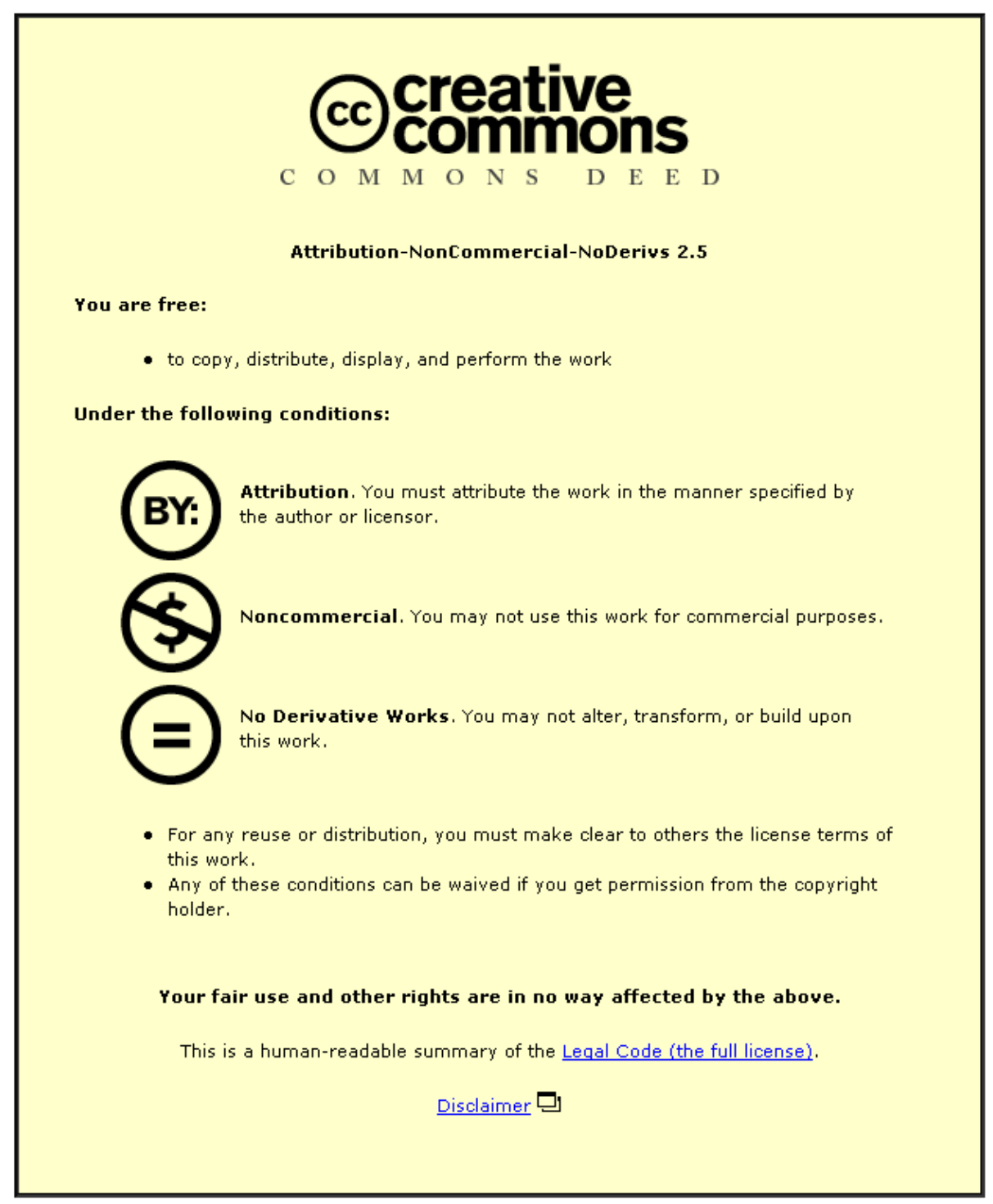

For the full text of this licence, please go to: http://creativecommons.org/licenses/by-nc-nd/2.5/ 


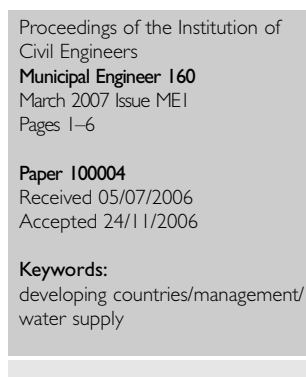

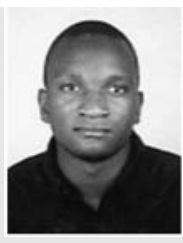

Josses Mugabi Doctoral candidate Water Engineering an Development Centre, Loughborough University, UK

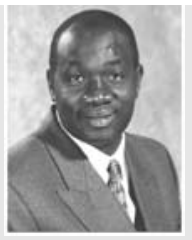

Sam Kayaga Assistant Programme Manager Water Engineering and Development Centre, Loughborough University, UK

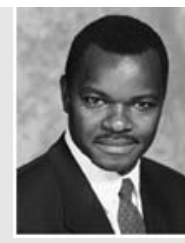

Cyrus Njiru

Principal Water Management Specialist, African Development Bank-African Development Fund, Tunis Belvedere, Tunisia

\section{Partnerships for improving water utility management in Africa}

\section{J. Mugabi MSc (Eng), S. Kayaga PhD, CEng, MCIWEM and C. Njiru PhD, MBA, MICE, CEng, MCIWEM}

\begin{abstract}
Urban water utilities in developing countries face enormous challenges in meeting the water needs of growing urban populations. Many of the challenges stem from poor utility management practices and the lack of a commercially oriented culture. For many years the debate on how to address this problem has been dominated by two extremes. On the one hand, private sector participation (PSP) has had only limited success. On the other, public management reform, which urges the creation of incentives for public utilities to become more efficient and commercially oriented, has not yet taken hold due to the slow pace of institutional reforms in developing countries. Given this situation, major players in the sector are seeking alternative approaches to improving utility management and performance in developing countries. Such alternative approaches include innovative multi-sector partnerships between private, public and civil society. This paper discusses a partnering approach (pioneered by the Water Utility Partnership (WUP) of Africa) between Loughborough University, Severn Trent Water, six African water utilities and utility management consultants. The aim of the partnership is to increase the management capacity of utility companies in order to improve the performance of water utilities in Africa. This innovative model has implications for policy and practice in this field.
\end{abstract}

\section{INTRODUCTION}

Clean drinking water shortages continue to be a significant problem in many parts of sub-Saharan Africa. The quality and coverage of services from most of the urban water utilities south of the Sahara remains poor. The situation is becoming worse with high urban population growth rates reported at 2-6\% per year, and sometimes higher. ${ }^{1}$ Keeping pace with the rapid urban population growth is a key challenge for urban water utilities in Africa. ${ }^{2}$ For a long time, measures taken by governments to address service coverage gaps have concentrated on building new infrastructure, with little attention given to improving the efficiency and productivity of water utilities. ${ }^{3}$ However, estimates of finance requirements for water and sanitation expansion point to large funding gaps ${ }^{4}$ and prospects of private sector investments appear bleak. This reality has compelled major players in the water sector to seek alternative approaches to improving water service coverage.
Such alternative approaches include capacity building through innovative multi-sector partnerships between public, formal and informal private sectors, as well as civil society. It is also becoming clear that the real potential for improvement in the African water sector lies in increasing the efficiency of existing systems. Reducing wastage, improving service quality and securing cash flows is a way forward to increasing coverage. This approach is consistent with the evolving 'soft path' to water, which argues for complementary investments in efficient technologies and human capital to increase service coverage. ${ }^{3}$ Investments in human capital include strengthening the management capacity of utilities companies. The availability of managers acquainted with modern utility management practices constitutes the basis for the execution of development programmes aimed at improving efficiency and productivity.

It is against this background that the Water Utility Partnership (WUP) of Africa, supported by the Swedish International Development Agency (SIDA), pioneered a capacity building (CB) partnership between Severn Trent Water (STW) (a UK private water utility), the Water, Engineering and Development Centre (WEDC) of Loughborough University (UK), independent utility management consultants from Africa and six African water utilities. The partnership arrangement was aimed at strengthening the management capacity of African water utilities to enable them to develop better strategies for improving their performance. This paper discusses the process, outcomes and challenges of this partnering approach and highlights important lessons for policy makers, both at sector and utility management levels. The paper also explores opportunities for scaling up the approach to other utilities in developing countries.

\section{CHALLENGES FACING WATER UTILITIES IN AFRICA}

Urban water utilities in Africa differ greatly in terms of size, organisational culture and operating environment. However, there are two major management challenges shared by all. First, the inefficiencies of water utility companies are a major cause of poor access to water services. In many systems as much as a third of production is lost through physical and commercial losses, and revenues are insufficient to cover operating costs let alone expand service coverage. ${ }^{5}$ Indeed, for African utilities, reduction of unaccounted-for-water (UfW) remains one of the major challenges. With growing urban populations, reducing wastage and losses has become a key strategic concern for utilities seeking to increase their service coverage. 


\begin{tabular}{|c|c|c|c|}
\hline Utility & Legal status and mandate & $\begin{array}{l}\text { Population service } \\
\text { coverage: } \%\end{array}$ & Level of UfW: \% \\
\hline $\begin{array}{l}\text { NWSC, Entebbe, } \\
\text { Uganda }\end{array}$ & $\begin{array}{l}\text { Government-owned utility; one of the I } 8 \text { major urban centres in } \\
\text { Uganda where NWSC is mandated to provide water/sewerage } \\
\text { services }\end{array}$ & 60 & 30 \\
\hline $\begin{array}{l}\text { MWAUWASA, } \\
\text { Mwanza, Tanzania }\end{array}$ & $\begin{array}{l}\text { Originally operated as a water services department under Mwanza } \\
\text { City Council; became fully autonomous in } 1998\end{array}$ & 70 & 57 \\
\hline $\begin{array}{l}\text { KIWASCO, Kisumu, } \\
\text { Kenya }\end{array}$ & $\begin{array}{l}\text { Private limited company incorporated in } 2001 \text { and wholly owned by } \\
\text { Kisumu Municipal Council }\end{array}$ & 20 & 70 \\
\hline $\begin{array}{l}\text { WASA, Maseru, } \\
\text { Lesotho }\end{array}$ & $\begin{array}{l}\text { Government-owned utility; one of the } 17 \text { major urban centres in } \\
\text { Lesotho where WASA is mandated to provide water/sewerage } \\
\text { services }\end{array}$ & 55 & 37 \\
\hline
\end{tabular}

A second problem facing utilities in Africa is that their management is usually not based on sound commercial principles. Owing to their public sector roots, many utilities still employ the traditional civil service/administrative style of management. There is lack of clarity in mandates and mission, lack of sound management structures and effective delegation, ineffective management information systems, poor customer service, and lack of human resources capacity.

Given these challenges, African governments have sought to implement institutional reforms to create incentives for utilities to become more efficient, accountable, commercially oriented and customer-focused. Although the reform process has progressed at a slow pace, many African countries have improved the institutional framework and made it possible for utilities to shift from crisis management to strategic planning and performance improvement. Through cooperation with skilled personnel and organisations from other countries, utility managers in Africa are now slowly beginning to make changes.

\section{RESPONDING TO THE CHALLENGE: CAPACITY BUILDING PARTNERSHIP APPROACH}

Multi-sector partnerships are widely promoted as mechanisms to improve access to water and sanitation services in developing countries. The underlying rationale for working in such partnerships is that each sector (public, private and civil society) possesses distinctive core competencies that, when combined, can help solve complex problems more effectively than any sector could do on its own. ${ }^{6}$ In addition, building partnerships between different sectors also creates opportunities for sharing experiences and capacity building. The WUP of Africa is an example of a partnership established primarily as a regional $\mathrm{CB}$ programme for water utilities in Africa. Launched in 1996, the WUP was conceived to spearhead, facilitate and organise advocacy and knowledge networks for African water utilities. WUP works by building partnerships among African water supply and sanitation utilities and other key sector institutions to create opportunities for sharing experiences and capacity building.

As part of its activities, WUP, supported by SIDA, initiated a CB partnership project in 2001 aimed at improving utility management and reduction of UfW. The project provided support to water utilities in six African countries (Uganda, Kenya, Tanzania, Lesotho, Benin and Congo). At the heart of this project was a novel partnership of international expertise and participating utilities, which allowed for $\mathrm{CB}$ using participatory approaches. STW in association with WEDC provided the international expertise. The participating utilities included: National Water and Sewerage Corporation (NWSC) in Entebbe (Uganda); Mwanza Urban Water and Sewerage Authority (MWAUWASA) in Mwanza (Tanzania); Kisumu Water and Sewerage Company (KIWASCO) in Kisumu (Kenya); Water and Sewerage Authority (WASA) in Maseru (Lesotho); Société Nationale des Eaux du Benin (SONEB) in Cotonou (Benin); and Société Nationale de Distribution d'Eau (SNDE) in Brazzaville (Congo). This paper draws on the experiences of the first four of the above utilities, which serve cities in Anglophone countries. The key background characteristics of these four utilities are given in Table 1.

\section{I. The partners}

Figure 1 shows a diagrammatic representation of the CB partnership developed to address management performance gaps in the six utility companies listed in Section 3. The logic of the partnership is based on the premise that local staff of the participating utilities know the prevailing situation and problems in their organisations, while external experts have knowledge of best practices and experiences from different parts of the world. STW and WEDC are two organisations with different but complementary competencies. Having undergone a major transformation from a public utility to a fully privatised ownership, STW has an excellent understanding of key performance indicators and commercial management of water utilities. On the other hand, WEDC has an excellent track record in education, training, research and consultancy for improved planning, provision and management of physical infrastructure and services in low- and middle-income countries, focusing on the needs of the poor. WEDC has also established a track record of undertaking $\mathrm{CB}$ work in the water and sanitation sectors.

Another innovative aspect of the partnership was the inclusion of regional utility management experts. These were independent consultants with significant utility management experience in their respective regions. These experts were brought on board to further enhance the understanding of local knowledge and context in order to develop appropriate results. The partnership also brought cross-fertilisation of knowledge and experience not only between the six participating utilities, but also with other African utilities considered to have best practices worth replicating elsewhere. Although the external research team did not have a formal relationship with these 'best practice' utilities 


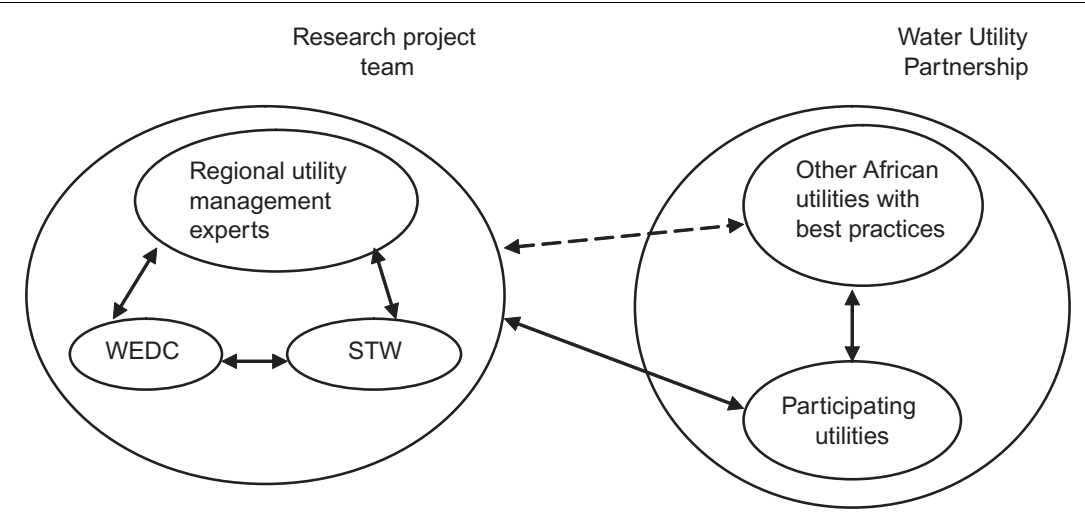

Fig. I. The capacity building partnership

(as indicated by the dotted line in Fig. 1), their inclusion in the learning network proved useful as they presented case studies of best practices in the region, allowed for exchange visits and peerreviewed performance improvement plans (PIPs) developed by the six participating utilities.

\subsection{Project scope, objectives and approach}

This CB partnership project was undertaken in two phases. Phase one was carried out in 2000/2001 when the participating utilities were selected and their performance assessed using universal evaluation criteria. Phase two of the project commenced in July 2003 and mainly involved developing critical management skills to enable participating utilities prepare their PIPs and action plans for the reduction of UfW. The specific objectives of the project were to

(a) improve the management skills of partner utilities through seminars, workshops, discussion groups, field trips, demonstrations and case studies

(b) support participating utilities in preparing their PIPs

(c) train participants and demonstrate the process of reducing UfW through the development of pilot zones

(d) bring together staff from different utilities in Africa to learn from each other

(e) disseminate the outcome of the $\mathrm{CB}$ partnership project to other African urban utilities.

A key feature of this partnership was that most of the tasks needed to achieve the objectives listed above were planned and carried out by staff from the participating utilities. The role of the research team was to facilitate and support the efforts of the utility staff in delivering the outputs. This approach ensured that the skills, knowledge and experience of the utility staff were easily applied and that the utility staff fully owned the outputs and outcomes of the partnership initiative. The approach of the participating utilities and external experts enhanced the creativity of the utility staff and enabled action learning.

\subsection{Developing performance improvement plans}

A key component of the CB partnership project was the concept of PIPs. A PIP is a comprehensive work plan developed to address a variety of management and technical issues that hinder an organisation achieving its objectives, strategy, mission and vision. In developing their PIPs, the water utilities carried out the following steps.
3.3.1. Institutional analysis. Senior and middle managers of participating utilities were facilitated to undertake a comprehensive analysis of strengths, weaknesses, opportunities and threats (SWOT) of their respective organisations. A political, environmental, social and technical (PEST) analysis was also undertaken for each organisation. Furthermore, managers of each utility carried out a preliminary analysis and formulation of objectives of their respective organisations, as well as preliminary plans and strategies for improvement. All these were discussed with stakeholders in a participatory way to solicit in-house consensus on the issues.

\subsubsection{Training and capacity building. After the institutional} analysis, four representatives from each water utility attended a two-week training course aimed at equipping participants with the critical management skills and knowledge necessary for developing and implementing effective PIPs. The training covered the following aspects
(a) institutional analysis and development
(b) commercialisation and customer services
(c) financial management
(d) management of human resources
(e) operation and maintenance management
(f) management of UfW
(g) contracting out utility activities and private sector participation (PSP)
(h) planning and development of PIPs
(i) case studies of management change programmes.

The training courses used a participatory approach, based on shared learning and experiences. A variety of $\mathrm{CB}$ tools were utilised including lectures, brainstorming, group discussions, peer reviews of presentations, field visits, demonstrations, discussions using cross-utility and working groups, benchmarking, case studies and debates. This diversity of tools was found to be conducive to learning. Furthermore, the sharing of participants' experiences and case studies of good practices from other utilities proved an effective mode of capacity building.

The key output of the training courses was an outline strategic planning framework for use in preparing the PIPs and action plans for reduction of UfW for each utility. The planning framework is illustrated in Fig. 2. In its simplest form, the purpose of a solution-oriented PIP is to answer the following four central 


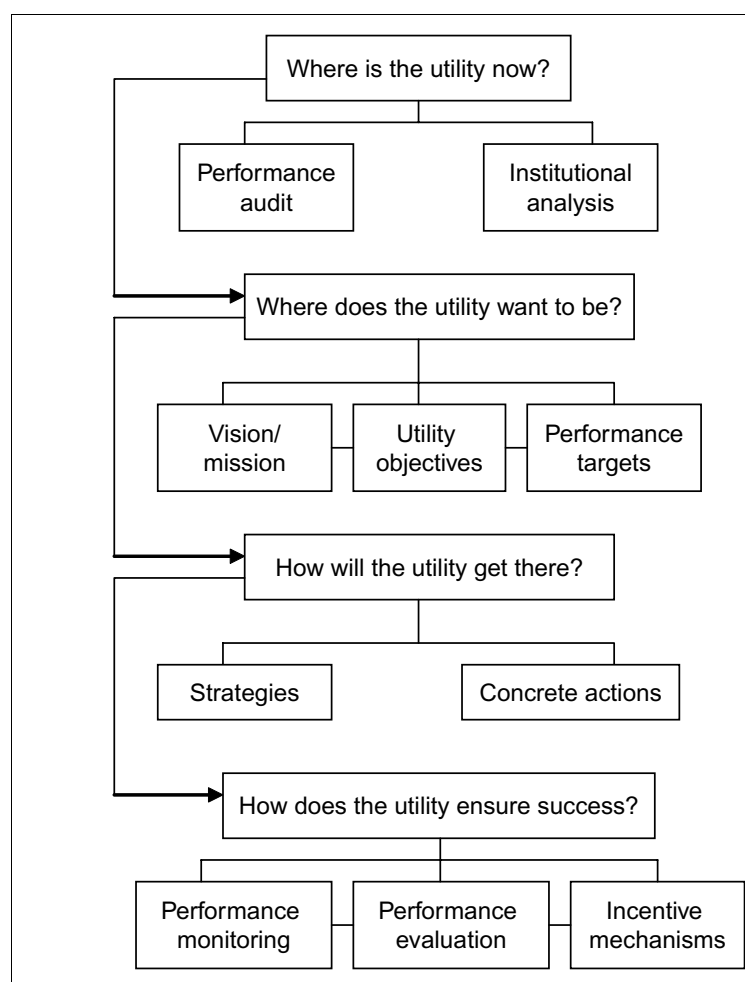

Fig. 2. Strategic planning framework for utility companies

questions. (a) Where is the utility now? (b) Where does the utility want to be? (c) How might the utility get there? (d) How does it ensure success? Each utility group presented their outline PIP to the whole group and received comments from other participants.

The course evaluations showed that the training provided a stimulating mix of learning methods that captured the interest of the participants throughout the two-week intensive course. The research team made follow-up visits to the utilities three months later to reinforce the knowledge and skills acquired during the course, and supported utility staff in applying these skills to prepare the PIPs. The follow-up visits enabled clarification and adaptation of some concepts from the course to each utility's operating environment.

3.3.3. Preparation of draft PIPs. Participants of the two-week intensive course became the nuclei of PIP task forces in their organisations, in which all departments were represented. These task forces embarked on the process of preparing draft PIPs soon after completion of the course. Using information revealed by institutional analysis, the task forces developed and clarified objectives in line with their respective vision and mission statements. To realise the corporate objectives, the PIP task forces developed departmental strategies, performance targets and detailed work plans over a planning horizon of five years. To develop these plans, the PIP task forces were supported by the research team during the short-term visits and back-stopping through email and telephone communications.

3.3.4. PIP review and finalisation. The draft PIPs for each utility were reviewed at two levels. Firstly, the PIP task force presented draft plans to an audience composed of the project research team and utility middle and senior managers at the 'home ground'. Secondly, a one-week seminar was held in Lusaka, Zambia, where each organisation presented their draft PIPs for peer review, discussion, comments and recommendations by the participating utilities and other invited water utility managers. The PIPs were finalised by incorporating recommendations that arose from the reviews. The PIPs were then subject to an approval process in their respective organisations.

\subsection{Partnership outcomes and challenges}

The partnership achieved a number of outcomes. Firstly, senior and middle managers of participating utilities were exposed to modern utility management practices through a comprehensive training programme. The major outcome of this training was the preparation of comprehensive utility PIPs, which have acted as a tool to implement significant process improvements and changes to enable each utility to achieve higher levels of performance. ${ }^{7-10}$

The plans produced by each utility are robust and follow best international practice. This indicates successful knowledge transfer. Although full implementation of the plans is dependent upon adequate financial resources, partner utilities have already registered significant achievements. Initial positive results emerging from the participating utilities include

(a) organisational restructuring to match organisational objectives and mission

(b) tailored management information systems (MISs) incorporating set objectives and targets

(c) better UfW reduction planning, which has already yielded results in some utilities

(d) application of financial modelling to strategic planning

(e) increased capacity of utility managers in strategic planning processes.

For some partner utilities, these qualitative changes may be responsible for positive trends in objectively quantifiable indicators. ${ }^{8}$ Table 2 shows the positive performance trend by MWAUWASA, whose robust MIS at the start of the project could enable comparative evaluation.

There were also a number of challenges and problems encountered. The major ones were as follows. In the first instance, there was a time lag of about two years between implementation of the two phases of the project. During this time there were significant changes in the staffing profile and, in some extreme cases, changes in the institutional set-ups of some of the utilities. Such situations required a revisiting of the concepts of the project right from the start in order to induct new staff into the project; this resulted in a waste of time and resources. Secondly, some utilities with a narrow financial base could not apply all the knowledge and skills obtained through the CB project, mainly because of lack of funds to purchase the necessary tools and equipment for piloting.

Thirdly, for some participating utilities, the CB partnership activities were not adequately mainstreamed within the organisation and in some instances the commitment of top management was low. Some senior and middle managers did not consider the CB activities as critical for organisational performance improvement. Instead, they considered the initiative as any other 'donor-funded project' in which they had to take time off their day-to-day duties to participate. Another major challenge was the lack of robust utility MISs at the start of the 


\begin{tabular}{|c|c|c|c|}
\hline & $2002 / 03$ & $2003 / 04$ & $2005 / 06$ \\
\hline Water produced per year: $000 \mathrm{~m}^{3}$ & 14279 & 14337 & 14280 \\
\hline Unaccounted for water: \% & 57 & 50 & 40 \\
\hline $\begin{array}{l}\text { Water supply area } \\
\text { coverage: } \%\end{array}$ & 70 & 72 & 82 \\
\hline Customer base (no. of connections) & 14515 & 16303 & 21340 \\
\hline Metered connections: \% & 76 & 89 & 97 \\
\hline Average water supply hours/day & 20 & 22 & 21 \\
\hline Sewerage service area coverage: \% & 7 & 7 & $8 \cdot 5$ \\
\hline Staff per 1000 connections & 14 & 12 & 10 \\
\hline Operating ratio & $0 \cdot 85$ & 0.96 & 0.8 \\
\hline Days receivable ration & 206 & 180 & 120 \\
\hline $\begin{array}{l}\text { Revenue collection } \\
\text { efficiency: \% }\end{array}$ & 94 & 95 & 97 \\
\hline
\end{tabular}

partnership. Many of the participating utilities rarely collected data systematically to enable a comparative evaluation of performance trends.

Finally, as is the case with multi-sector partnerships of this nature, there was the usual conflict of values, meanings and methodologies that had to be resolved in order to keep the partnership on track. Although such conflicts might have, in some instances, led to delays in implementation of activities, they also helped to broaden partnership perspectives and enhance respect and trust among the stakeholders.

\section{POLICY LESSONS}

The CB partnership approach discussed in this paper has important lessons for policy makers. At the sector level, the approach provides a potentially effective and sustainable route for donor agencies supporting water utility reform in Africa. Usually, bilateral and multilateral technical support to developing countries is delivered through a traditional 'consultancy' approach in which international consulting organisations or individuals are recruited as technical advisors on a long-term basis to evaluate, design and implement the reforms as they are being understudied by counterpart staff. Such an approach is expensive and, in many case, social, cultural and political perspectives have not favoured the learning process to progress as anticipated.

The results of this project also reinforce the crucial lesson that $\mathrm{CB}$ may be able to improve the performance of water utilities where PSP has failed. The two-week training module offered as part of the project precipitated significant changes in the capacity and attitudes of the participants. Not only were the participants exposed to the concepts and application of contemporary water utility management, but the social interaction of participants from different organisational and social cultures also created an atmosphere of ideas exchange and adaptive learning. With the mixed results coming out of PSP in urban water supply in several African countries, it may be worthwhile revisiting the earlier emphasis of committing adequate resources into capacity building.

A key lesson for water utility managers is that comprehensive strategic planning is a crucial part of efforts to improve utility performance. The PIP framework developed as part of the project (see Fig. 2) can be adapted by other utilities to develop comprehensive strategic work plans that address a variety of technical and management issues with the aim of improving utility performance and achieving short-, medium- and longterm objectives.

\section{OPPORTUNITIES FOR SCALING UP THE CB APPROACH}

Despite decades of donor-supported investments, many lowincome countries, especially in Africa, are still unable to fully meet the demand for water and sanitation services in their areas of jurisdiction. Experience in these countries has revealed that service problems are mainly caused by management and institutional deficiencies. PSP by multinational water companies currently being promoted has not provided the level of improvement expected in many countries and some PSP contracts have subsequently been terminated prematurely. ${ }^{11}$ Public utilities are therefore likely to dominate water service provision in many developing countries for decades to come. To address the problems faced by public utilities, alternative approaches must be developed to facilitate improved service delivery. CB partnerships offer a real opportunity to address management deficiencies and help utility companies to adopt a commercially oriented culture.

The CB approach discussed in this paper could be scaled up to involve more utilities. Scaling up could be achieved either through a new WUP initiative or through brokering and strengthening collaboration between utilities that have participated in the current CB partnership and those that have not. A new initiative similar to the current programme would undoubtedly require more funding, which may not be readily available within WUP. Nonetheless, it is worth making some general recommendations for any such initiatives that may be implemented in the future. Firstly, the selection criteria for participating utilities should put more emphasis on the willingness of top management to improve the performance of the utility. Experience with the current initiative has shown that the responsiveness and buy-in of top management to partnership activities is a key success factor. More resources should perhaps be spent on advocacy with and mobilisation/education of senior management staff. Secondly, given the institutional environment in developing countries, it is important that flexibility is built into the timing and length of international expert visits and other partnership inputs. 
A further opportunity for scaling up the CB approach is through regional inter-utility collaboration. In particular, there is potential for knowledge and skills transfer through collaborative arrangements between utilities that have participated in the current $\mathrm{CB}$ initiative and those that have not. For instance, NWSC (Uganda) recently established an external services unit within the organisation to provide a wide range of utility management advisory services to other utilities in the region. Collaboration already exists between NWSC and other water utilities in Dar es Salaam (Tanzania), Lusaka (Zambia) and Nairobi (Kenya). ${ }^{12}$ More collaborative arrangements of this nature could be promoted by WUP as a way of spreading best practices to a wider regional network of water utilities.

\section{CONCLUSION}

Building partnerships among water utilities and other sector institutions creates opportunities for sharing experiences and CB. The experience in Africa reported here shows that a well-crafted multi-sector CB partnership between water utilities in developing countries, international/regional expertise and training/research organisations has the potential to build critical management skills and improve performance. The logic of the partnership was based on the premise that local staff of participating utilities and regional utility management experts have knowledge of the operating environment and problems in the organisation, while external experts have knowledge of best practices and experiences from different parts of the world. At the heart of the partnership was a participatory approach in which international/regional experts working with a training organisation acted as facilitators while utility managers planned and produced the intended outputs. The resulting partnership of international expertise and local knowledge played a crucial part in addressing many performancerelated problems of the partner utilities.

\section{ACKNOWLEDGEMENTS}

The action research leading to this paper was sponsored by the Swedish International Development Cooperation Agency (SIDA) as part of a study for the benefit of developing countries. The views expressed are not necessarily those of SIDA. The authors are grateful for the efforts of all members of the international research team, the Water Utility Partnership (WUP) of Africa, and management and staff of the participating utilities for their cooperation and dedication during the research study.

\section{REFERENCES}

1. NJIRU C. and SANSOM K. Strategic marketing of water services in developing countries. Proceedings of the Institution of Civil Engineers, Municipal Engineer, 2003, 156, No. 2, 143-148.

2. Water Utility Partnership. Better Water and Sanitation for the Urban Poor: Good Practices from Sub-Saharan Africa. WUP, Kenya, 2003.

3. WolfF G. and Gleick P. The soft path for water-The World's Water: 2002-2003. Island Press, Washington DC, 2002.

4. Water and Sanitation Program. Financing the Millennium Development Goals for Water and Sanitation. Water and Sanitation Program, Nairobi, Kenya, 2005, Sector Finance Working Paper No. 10.

5. WORLD BANK. Reforming Infrastructure: Privatisation, Regulation and Competition. World Bank Policy Research Report. Oxford University Press, Oxford, 2004.

6. Mathews P. Multi-sector partnerships for poverty reduction. Proceedings of the Institution of Civil Engineers, Engineering Sustainability, 2005, 158, No. 1, 5-7.

7. Tumuheirwe S., LutAaya M. and Kayaga S. Improving utility management through partnership and capacity building. Proceedings of the 31st WEDC International Conference, Kampala, Uganda, 2006, 266-269.

8. МiнаYо Z. and NJIRU C. Improving utility management: case study of MWAUWASA. Mwanza Tanzania. Proceedings of the 31 st WEDC International Conference, Kampala, Uganda, 2006, 196-199.

9. Kayaga S., NJiru C., Itiko M. and OnYango-Awin J. Improving utility management: case study from Kisumu. Kenya. Proceedings of the 31 st WEDC International Conference, Kampala, Uganda, 2006, 172-175.

10. Sexhonyana S., Pholo M. T. and Fisher J. Improving utility management: case study from Lesotho. Proceedings of the 31st WEDC International Conference, Kampala, Uganda, 2006, 254-257.

11. Izaguirre A. K. and Hunt C. Private water projectsinvestments up by $36 \%$ in 2004 . See http://rru.worldbank.org/Documents/ PublicPolicyJournal/297Izaguirre.pdf for further details.

12. National Water and SeWerage Corporation (NWSC) Uganda. NWSC External Services. See http://www.w1.co.ug/external\%20services/ external_services.htm for further details.

\section{What do you think?}

To comment on this paper, please email up to 500 words to the editor at journals@ice.org.uk

Proceedings journals rely entirely on contributions sent in by civil engineers and related professionals, academics and students. Papers should be $2000-5000$ words long, with adequate illustrations and references. Please visit www.thomastelford.com/journals for author guidelines and further details. 